The Canadian Journal of Higher Education, Vol. XXIII-3, 1993

La revue canadienne d'enseignement supérieur, Vol. XXIII-3, 1993

\title{
Using the Delphi Method to Improve the Curriculum
}

\section{SHIRLEY BLAIR* \& NORMAN P. UHL*}

\begin{abstract}
An example of employing the Delphi technique for curriculum improvement at a Canadian university is described. This technique was used to identify essential course components to be included in a revised Office Administration program. In addition to providing the necessary information for updating and improving the curriculum, the Delphi technique allowed the department to receive information from and educate guidance counsellors and future employers with regard to the proposed changes in the program. The Delphi technique made it possible to obtain opinions from five diverse groups at relatively low cost and effort. The anonymity that the Delphi method provides helped to ensure that responses reflected accurately the opinions of the respondents. A number of areas of study and special competencies and skills were identified as being essential to a program designed to meet the needs of the automated workplace. The study determined that the program should encompass a much larger component in office technology than existed previously and that the focus of the program should be on information management rather than office administration. Along with the methodology, the advantages and disadvantages of using the Delphi technique for improving the quality of the curriculum are discussed.
\end{abstract}

* Mount Saint Vincent University 


\section{Résumé}

L'article décrit un exemple de l'emploi de la technique Delphi dans une université canadienne en vue d'améliorer un programme d'études. L'emploi de cette méthode a permis d'identifier les composants essentiels des cours à inclure dans un programme d'administration de bureau rénové. En plus de fournir les données nécessaires à la mise à jour et à l'amélioration du programme, la technique Delphi a rendu possible un échange d'information permettant notamment au département d'éduquer les conseillers d'orientation et les futurs employeurs quant aux modifications proposées pour le programme. La technique Delphi a permis de consulter cinq groupes différents pour un coût et un effort relativement modérés. L'anonymité garantie par les procédures de la méthode a permis d'assurer que les réponses reflétaient fidèlement les opinions des répondants. Plusieurs domaines d'études et plusieurs compétences et savoirfaire spécifiques ont été identifiés comme essentiels à un programme visant à répondre aux besoin d'un lieu de travail automatisé. L'étude a déterminé que le programme devrait comprendre un composant en étude de bureautique beaucoup plus étendu que celui qui existait auparavant et qu'il devrait être davantage centré sur la gestion de l'information que sur l'administration de bureau. L'article présente la méthodologie et discute les avantages et désavantages de la technique Delphi pour la révision des programmes.

With the recent emphasis on quality of education (Conrad \& Blackburn, 1985; Smith, 1991; Bogue \& Saunders, 1992), it is important to identify useful methods for improving the curriculum. A procedure which has been used successfully for this purpose in the United States is the Delphi technique (Uhl, 1990). This method has been used in Canada as a forecasting tool and as a method of obtaining convergence of opinion (Nadeau et al., 1992), but rarely has it been reported in publications as being used for curriculum improvement.

An objective of the Delphi technique is to obtain convergence of opinion without bringing individuals together in face-to-face meetings. This objective is usually achieved by having the participants complete a series of questionnaires interspersed with controlled opinion feedback. This mode of controlled interaction among the respondents not only leads to savings in time and money, but also permits independent thought among participants and assists them in the gradual formation of a considered opinion. It has the added advantage of ensuring participants' anonymity. In contrast, direct confrontation, as experienced in faculty or committee meetings, often results in hasty offering of preconceived notions, the inclination to close one's mind to novel ideas, a tendency to defend 
previously taken stands, and a tendency to be influenced by the persuasively stated opinions of others.

The general procedure for the Delphi technique is as follows:

1. The participants are asked to list their opinions on a specific topic such as curriculum revision or planning priorities.

2. The participants are then asked to evaluate the total resulting list by a criterion such as importance, chance of success, and so on.

3. The participants receive the list and a summary of responses to the items. If the participants are in the minority, they are asked to revise their opinions or indicate their reasons for remaining in the minority.

4. The participants again receive the list, an updated summary, minority opinions, and another chance to revise their opinions.

The use of the Delphi technique may be warranted if any or all of the following conditions exist: (1) the resolution of a problem can be facilitated by the collective judgments of one or more groups; (2) those groups providing judgments are unlikely to communicate adequately without an intervening process; (3) the solution is more likely to be accepted if more people are involved in its development than would be possible in a face-to-face meeting; (4) frequent group meetings are impractical because of time, distance, and so forth; and (5) one or more groups of participants are more dominant than another (Uhl, 1983).

The following describes the employment of the Delphi technique to improve the curriculum of an office administration program in a relatively small university (approximate FTE of 4000) in Nova Scotia.

Prior to this Delphi study, the faculty of the Department of Office Administration had been meeting to develop a revised program which it hoped would better serve the needs of the marketplace. As it developed a proposed new program, the faculty thought it would be beneficial to obtain from different groups reactions to the proposed changes and suggestions for additional changes. Several groups from which reactions would be helpful were identified. These included the department's advisory board, graduates of the department since 1980, students presently enroled in the department, a selected group of Atlantic Canadian businesses, and high school guidance counsellors in the province. These five groups were selected either because of their unique positions as stakeholders in the proposed curriculum revisions or because they were considered to be "experts" who would very likely contribute useful and timely information. The fact that all of these groups were considered to have a valuable 
contribution to make even though they were, to some extent, widely divergent, necessitated the use of a method which might provide adequate communication among the groups in the form of feedback of opinions of other respondents. Meetings either within or between these groups were not practical because of time, geographic and fiscal constraints. Furthermore, had it been feasible to bring these groups together, it is likely that certain groups would have tended to dominate, as a result of their greater experience, maturity, and positions in the business community. For these reasons, therefore, the Delphi technique was selected as the best method for obtaining information, gaining the greatest degree of participation and achieving some convergence of opinion among these different groups.

\section{Method}

\section{Subgroups}

The five subgroups included all 12 members of the department's advisory board, 60 representatives from Atlantic Canadian businesses, all 220 Office Administration Department degree graduates from 1980 to the present, Nova Scotia high school guidance counsellors, and students presently enrolled in the department's programs. The Eastern Canadian businesses were chosen on the basis of size as well as prominence in their communities and their industries. The 54 guidance counsellors were from the largest high schools in the province. Returning students in good academic standing who were enrolled in the program above first year level were selected.

\section{Questionnaire Development}

In developing the first questionnaire, material was first reviewed from universities which had been involved in Office Administration curriculum revisions. With this information as a background, the first-round questionnaire was developed in consultation with the department. This questionnaire was pretested on a graduate class in Education composed of guidance counsellors, and on some Office Administration faculty and three members of the business community. The questionnaires for rounds two and three were developed on the basis of the responses received to this first questionnaire. The second and third questionnaires reflected the responses of the previous rounds. Consistent with the Delphi procedure, these questionnaires were designed to give the respondents as much feedback as possible on the responses of the group to each question in the preceding questionnaire. Table 1 shows examples of types of questions in the 
three rounds of questionnaires. The questions from rounds two and three show how feedback on responses of other participants was given to respondents to assist them in their decision-making. The Round One questionnaire contained more open-ended questions, as opinions were sought concerning components that should be included in future rounds. The subsequent rounds then contained more questions using Likert-type scales.

\section{Procedure}

Three rounds of questionnaires with covering letters (available from the senior author) were sent over a period of eight months. Before the first mailing, letters were sent to the superintendents of every school district involved, asking if any objected to a polling of the opinions of guidance counsellors in their districts. Some superintendents responded with written permission. None refused permission. After the first round, the second round of questionnaires was sent to business and student subgroups who had responded to the first round. The guidance counsellors had a very low rate of response in the initial round (17\%) and expressed concern with regard to their inadequate knowledge of the program and its graduates. Therefore this whole group was sent a revised cover letter to explain their role in the study, along with the second questionnaire. In addition, the second round was sent to all graduates who had responded to the first round, as well as to an additional 15 selected from the list of those who had been sent the first questionnaire and had not replied. (Before selecting these 15, names of all those graduates whose questionnaires had been returned as undeliverable were eliminated from the original list.) These additional graduates were added to the second round because of the relatively low response (32\%) of graduates to the first round. The remaining three groups were considered to have an acceptable rate of return after the first round. It was recognized at the outset that the graduate population is a mobile one and that many of the addresses on record at the University would be out of date. Although every effort was made to acquire the most recent addresses, a large group of graduates was sent the first round in order to compensate for an anticipated low rate of return. The Advisory Board was not asked to complete the second questionnaire as they were involved in discussions with the faculty at the time and were providing feedback and recommendations. This group, therefore, received only the first and third rounds.

The third-round questionnaires were sent to the same people to whom the second round had been sent, with the exception of those whose questionnaires had been undeliverable during the second round and the addition of the Advisory Board. 
Table 1

Sample Questions from Three Rounds

Round

\section{Question}

One 2.(a) In order to develop courses that will prepare the type of graduate competent in the areas identified by you in Question One, please rate the following competencies to indicate, by circling the appropriate number, the degree of competence which you consider necessary for students in this program.

\section{Very competent Fairly competent Not Necessary}

$\begin{array}{llll}\text { Keyboarding } & 1 & 2 & 3 \\ \text { Training skills } & 1 & 2 & 3 \\ \text { Records management } & 1 & 2 & 3\end{array}$

2.(b) Please add competencies that you think should have been included in the preceding list as well as any comments you may have.

Two 2. In order to develop courses that will prepare the type of graduate competent in the areas identified by the Department and by you in Round One, please rank the following competencies. Please indicate, by circling the appropriate number, the importance of each competency to students in this program. Underlined numbers indicate the majority response from Round One. If you agree with the previous majority response, circle this number. If you disagree, please circle your choice and, if you wish, give reasons for doing so. Note that new items have no underlined number as there was no previous response. For each item, please select very important (1), fairly important (2), or not important (3)

$\begin{array}{lllll} & & & & \begin{array}{l}\text { Reasons for choice } \\ \text { if outside majority. }\end{array} \\ \text { Keyboarding } & \underline{1} & 2 & 3 & \\ \text { Training skills } & 1 & 2 & 3 & \\ \text { Records management } & 1 & \underline{2} & 3 & \\ \text { Work flow analysis } & 1 & 2 & 3 & \end{array}$


Table 1 (cont'd)

Three In order to develop courses that will prepare the type of graduate competent in the areas identified (both by the Department and by you) in Question One, please rate the following competencies. Please indicate, by circling the appropriate number, the importance of each competency to students in this program. Underlined numbers indicate the majority response for items in Round Two for which a consensus was not reached. If you agree with the previous majority response, circle this number. If you disagree, please circle your choice. Items for which a consensus was reached are indicated in the appropriate columns. The right-hand column summarizes reasons given by some respondents for not choosing the majority (underlined) selection. Only reasons cited by at least two people are included.

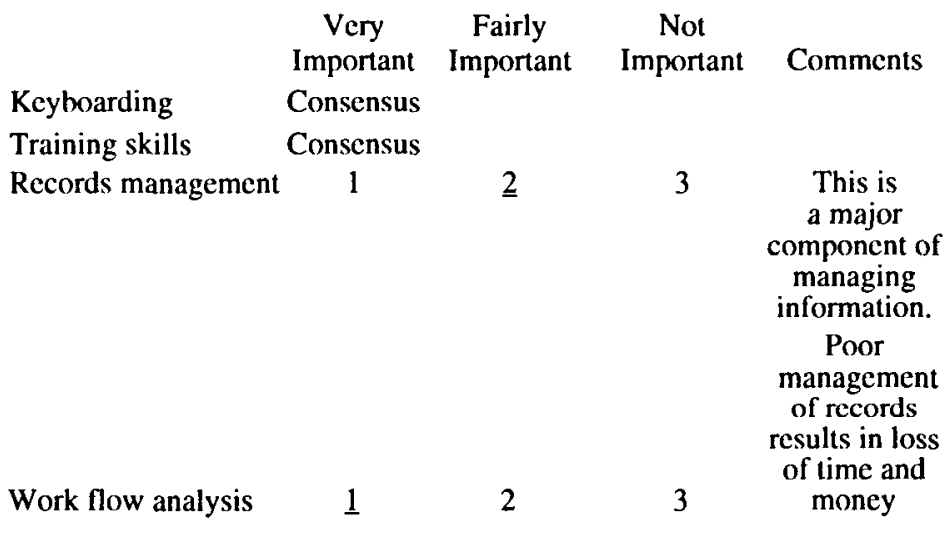

In the analysis of the data, frequencies were calculated for each element in all three rounds of questionnaires in order to give feedback percentages to respondents during the rounds and to determine if and when consensus was achieved. Consensus was defined as $85 \%$ agreement. This was done for the whole group in each round as well as for all subgroups in each round.

In addition, the 61 respondents who had answered all three questionnaires were tracked, and frequencies and means and standard deviations were calculated for this group. This allowed a comparison of the responses of this group with responses of those who completed at least one round. The comparison provided reassurance that congruence had not occurred as a result of those in disagreement with the majority not completing later rounds. 


\section{Results}

Table 2 shows the response rates for each subgroup in the three rounds. From a total of 386 questionnaires sent in the first round there were 151 returned (40\%). Second-round questionnaires were sent to a total of 192 individuals and 102 (53\%) completed them. As previously explained, the second round did not include the Advisory Board. Third-round questionnaires were sent to 194 individuals and $97(50 \%)$ were completed. The larger number for round three, despite some attrition, is due to the inclusion of the 12 Advisory Board members who were not sent questionnaires in round two. During the three rounds, there was some attrition in the Business sub-group due, in part, to the very unstable economy during this period. This economic instability, which led to personnel transfers and loss of jobs, may have also contributed to attrition in the graduate sub-group.

There were three main areas investigated in the three rounds of questions: (1) the general areas of expertise that the respondents perceive as essential to graduates of this program, (2) the key elements (competencies) which should be included in the program, and (3) the types of occupations that these graduates would be expected to fill. In addition, respondents were asked their opinions concerning the efficacy of including co-op work terms in the program and for input on how they thought the focus of the program should change.

\section{Areas of Expertise}

Consensus was reached concerning the following areas: the introduction of new technology; linkage of existing technology and computer systems in the workplace; managing the impact of technology on the type of work done and the way in which that work is done in a business environment; managing information in the business environment; and management of the impact of technology on people and its effect on their satisfaction, motivation, and performance.

\section{Competencies}

Throughout the three rounds of questionnaires, respondents were asked their opinions concerning the degree of competence needed by graduates in various specific skills and knowledge areas. The original list of 23 competencies in Round One was expanded to 34 in Round Two as a result of suggestions from respondents to the first questionnaire. Table 3 shows frequencies for responses concerning competencies.

Since the response rate was not always consistent (for example, some people responded to Rounds One and Three, but not to Round Two), Table 4 shows 
Table 2

Response Rates

\begin{tabular}{|c|c|c|c|c|c|c|c|c|c|}
\hline \multirow{2}{*}{ Subgroups } & \multicolumn{3}{|c|}{ Round 1} & \multicolumn{3}{|c|}{ Round 2} & \multicolumn{3}{|c|}{ Round 3} \\
\hline & Sent & Returned & Rate & Sent & Returned & Rate & Sent & Returned & Rate \\
\hline Advisory Board & 12 & 9 & $75 \%$ & N/A & N/A & $N / A$ & 12 & 7 & $58 \%$ \\
\hline Business & 60 & 27 & $45 \%$ & 25 & 22 & $85 \%$ & 24 & 17 & $71 \%$ \\
\hline Graduates & 220 & 72 & $33 \%$ & 80 & 38 & $48 \%$ & 75 & 34 & $45 \%$ \\
\hline Guidance Counsellors & 54 & 9 & $17 \%$ & 54 & 19 & $35 \%$ & 52 & 15 & $29 \%$ \\
\hline Students & 40 & 34 & $85 \%$ & 33 & 23 & $70 \%$ & 32 & 24 & $75 \%$ \\
\hline TOTAL & 386 & 151 & $40 \%$ & 192 & 102 & $53 \%$ & 195 & 97 & $50 \%$ \\
\hline
\end{tabular}

Note: Advisory Board did not participate in Round Two. 
Table 3

Frequencies in Percentages for Competencies: All Respondents

\begin{tabular}{|c|c|c|c|c|c|c|c|c|c|}
\hline \multirow{2}{*}{ Competencies } & \multicolumn{3}{|c|}{$R 1(N=151)$} & \multicolumn{2}{|c|}{$\mathrm{R} 2(\mathrm{~N}=102)$} & \multicolumn{3}{|c|}{$\mathrm{R} 3(\mathrm{~N}=97)$} & \multirow[b]{2}{*}{ NI } \\
\hline & VI & FI & NI & VI & $\mathrm{FI}$ & NI & VI & FI & \\
\hline Keyboarding & 72.8 & 25.8 & 1.3 & 87.3 & 10.8 & 2.0 & C & - & - \\
\hline Proofreading & 80.8 & 15.2 & 4.0 & 92.2 & 4.9 & 2.9 & $\mathrm{C}$ & - & - \\
\hline Written Communication Skills & 92.1 & 7.9 & 0.0 & 98.0 & 2.0 & 0.0 & $\mathrm{C}$ & - & - \\
\hline Oral Communication & 89.4 & 9.9 & 0.7 & 99.0 & 1.0 & 0.0 & $\mathrm{C}$ & - & - \\
\hline Records Management & 44.6 & 53.4 & 2.0 & 42.6 & 55.4 & 2.0 & 51.5 & 48.5 & 0.0 \\
\hline Word Processing & 83.3 & 16.0 & 0.7 & 98.0 & 2.0 & 0.0 & $\mathrm{C}$ & - & - \\
\hline Spreadsheets & 49.7 & 47.0 & 3.3 & 88.1 & 11.9 & 0.0 & $\mathrm{C}$ & - & - \\
\hline Databases & 53.0 & 45.0 & 2.0 & 95.0 & 5.0 & 0.0 & $\mathrm{C}$ & - & - \\
\hline Graphics & 28.5 & 57.0 & 14.6 & 22.8 & 75.2 & 2.0 & 25.8 & 73.2 & 1.0 \\
\hline Accounting Software & 33.1 & 58.3 & 8.6 & 27.7 & 70.3 & 2.0 & 25.8 & 70.1 & 4.1 \\
\hline Desktop Publishing & 29.1 & 59.6 & 11.3 & 24.8 & 71.3 & 4.0 & 26.8 & 69.1 & 4.1 \\
\hline Decision Support Software & $*$ & $*$ & $*$ & 32.7 & 57.1 & 10.2 & 14.4 & 81.4 & 4.1 \\
\hline CAD/Engineering Software & $*$ & $*$ & $*$ & 20.2 & 48.5 & 31.3 & 4.1 & 62.9 & 33.0 \\
\hline Business Statistics & 17.2 & 68.2 & 14.6 & 12.7 & 81.4 & 5.9 & 15.5 & 74.2 & 10.3 \\
\hline Research Methods & 23.2 & 60.9 & 15.9 & 11.8 & 79.4 & 8.8 & 18.6 & 70.1 & 11.3 \\
\hline Telecommunications & 54.3 & 42.4 & 3.3 & 88.2 & 11.8 & 0.0 & C & - & - \\
\hline Office Environment Planning/Design & 36.4 & 53.6 & 9.9 & 25.5 & 74.5 & 0.0 & 23.7 & 70.1 & 6.2 \\
\hline Systems Analysis & 40.9 & 51.0 & 8.1 & 18.8 & 72.3 & 8.9 & 21.6 & 74.2 & 4.1 \\
\hline Equipment Selection & 47.0 & 41.1 & 11.9 & 34.7 & 59.4 & 5.9 & 45.8 & 49.0 & 5.2 \\
\hline Software Evaluation & 50.3 & 40.4 & 9.3 & 84.2 & 9.9 & 5.9 & C & - & - \\
\hline
\end{tabular}


Table 3 (cont'd)

\begin{tabular}{|c|c|c|c|c|c|c|c|c|c|}
\hline \multirow{2}{*}{ Competencies } & \multicolumn{3}{|c|}{$\mathrm{R} 1(\mathrm{~N}=151)$} & \multicolumn{2}{|c|}{$\mathrm{R} 2(\mathrm{~N}=102)$} & \multicolumn{3}{|c|}{$\mathrm{R} 3(\mathrm{~N}=97)$} & \multirow[b]{2}{*}{ NI } \\
\hline & VI & FI & NI & VI & FI & NI & VI & FI & \\
\hline Training Skills & 58.7 & 36.7 & 4.7 & 91.0 & 8.0 & 1.0 & $\mathrm{C}$ & - & - \\
\hline Computer Programming & 24.5 & 43.7 & 31.8 & 14.9 & 65.3 & 19.8 & 11.3 & 63.9 & 24.7 \\
\hline Business Ethics & 65.6 & 31.8 & 2.6 & 91.2 & 8.8 & 0.0 & $\mathrm{C}$ & - & - \\
\hline Voice Processing Management & 25.8 & 62.3 & 11.9 & 24.0 & 70.0 & 6.0 & 23.7 & 74.2 & 2.1 \\
\hline Supervisory Skills & 56.7 & 38.0 & 5.3 & 86.3 & 12.7 & 1.0 & $\mathrm{C}$ & - & - \\
\hline Support Systems Analysis & $*$ & $*$ & $*$ & 26.7 & 63.4 & 9.9 & 24.7 & 71.1 & 4.1 \\
\hline Project Management & * & * & * & 47.5 & 43.6 & 8.9 & 83.5 & 15.5 & 1.0 \\
\hline Time Management & $*$ & * & * & 81.4 & 17.6 & 1.0 & 93.8 & 6.2 & 0.0 \\
\hline Work Flow Analysis & * & * & * & 55.9 & 41.2 & 2.9 & 83.3 & 15.6 & 1.0 \\
\hline Hardware Configuration & $*$ & * & * & 17.8 & 64.4 & 17.8 & 18.6 & 74.2 & 7.2 \\
\hline Business Process Design & * & * & * & 15.8 & 72.3 & 11.9 & 10.4 & 88.5 & 1.0 \\
\hline Operating Systems & $*$ & * & $*$ & 50.0 & 42.2 & 7.8 & 78.4 & 16.5 & 5.2 \\
\hline Micrographics/Electronic Imaging & $*$ & $*$ & $*$ & 8.9 & 71.3 & 19.8 & 7.2 & 81.4 & 11.3 \\
\hline Team Building Skills & $*$ & * & $*$ & 74.5 & 24.5 & 1.0 & 86.6 & 13.4 & 0.0 \\
\hline
\end{tabular}

Note I: Asterisks in some categories for Round One indicate competencies which did not appear in that round. These competencies were included in subsequent rounds as a result of Round One responses.

Note II: "C" indicates the point where consensus ( 85 percent) was reached in the previous round and the element was dropped from subsequent rounds.

VI $=$ Very Important

FI = Fairly Important

$\mathrm{NI}=$ Not Important 
frequencies for competencies for those who responded to all three rounds. These figures indicate that frequencies for competencies selected by respondents who replied to all three rounds of questionnaires appear to be fairly consistent with results for the whole group (those who responded to at least one round).

\section{Occupations}

Respondents were asked their opinions concerning various occupations for which a program graduate might qualify. There were two underlying reasons for doing this. First, the department was looking for some assurance that this program was being designed to fill occupational niches that actually exist. Second, since some of the members of several subgroups are potential employers, it was a good opportunity to encourage them to begin to think of the graduates as having the education and skills to fill positions in their organizations. Table 5 shows the frequency responses in percentages during three rounds of questions on possible occupations for the new graduate. Respondents were asked to indicate whether a new graduate could, in their opinion, fill the suggested occupations immediately after graduation or after acquiring some experience. In Round One respondents were given the option of answering either "Immediately," With Experience," or "Never." "Never" was chosen for occupations which many respondents thought were inappropriate for these graduates. There was also a tendency to select "immediate" for these positions and then add a comment that it was really an inappropriate position for such a graduate. In subsequent rounds, therefore, these occupations were dropped from the questionnaires; but others were added as a result of suggestions in Round One. Occupations which received a relatively high rating of "never" (over 15\%) or "immediate" together with negative comments, and were therefore dropped, included receptionist, data processing operator, file clerk, and MIS manager. Comments suggested that the first three were rated "never" because the graduate would be overqualified for such positions. The fourth was considered by respondents to be outside the sphere of expertise for graduates of this program.

Although Table 5 indicates that many of the occupations could not be filled immediately by new program graduates, but only after some experience, a majority of respondents indicated that they would consider four co-op work terms sufficient experience for many of the occupations. In this instance, the occupations most frequently listed included trainer, administrative services supervisor, records analyst, and office automation analyst. Over $98 \%$ of the respondents supported the inclusion of some type of work experience in the program. Scheduled work terms were most often recommended. 
Table 6 shows the frequency responses for occupations from all those who responded to all three rounds. As with competencies, there were no significant differences between the responses of this group and those of the whole group.

Ninety-two percent of all respondents agreed that the emphasis of the program should move from office administration to information management. Of those who did not agree, many simply wanted another label instead of "information management," although they were describing the same concept.

\section{Discussion of the Results}

While consensus was reached on several of the competencies and there was majority agreement on most, there were still others where very little agreement was reached. There was a fairly even split between people who considered equipment selection to be very important and those who considered it only fairly important. There was also substantial disagreement concerning the degree of importance of office environment planning, as well as desktop publishing, accounting software, systems analysis, and voice processing management. There could be several reasons for these results. In some instances, such as systems analysis, comments were made that respondents did not have a clear understanding of what was involved in a particular competency. This was especially true with the counsellors' subgroup where the respondents repeatedly mentioned that they were not qualified or not sufficiently well informed to give an opinion.

There was almost universal agreement concerning some competencies. These were generally areas in which high agreement was anticipated. For example, it was anticipated that both written and oral communication would be rated as very important. Somewhat surprisingly, keyboarding was rated as a very important element to be included in the program. Faculty had concluded that since keyboarding courses were offered in most high schools, it was no longer essential to include the teaching of such a skill at the postsecondary level. (Keyboarding is now planned as a short non-credit course for students who enter the program without this skill.)

Throughout the three rounds there was movement of the whole group toward increasing the importance assigned to knowledge of software applications such as word processing, spreadsheets, and databases. This was also true of the competencies of software evaluation, training skills, and telecommunications.

On the other hand, there was little movement throughout the three rounds in areas such as computer programming and research methods. While this was 
Table 4

Frequencies in Percentages for Competencies: Respondents to All Three Rounds

\begin{tabular}{|c|c|c|c|c|c|c|c|c|c|}
\hline \multirow{2}{*}{ Competencies } & \multicolumn{3}{|c|}{$R 1(N=61)$} & \multicolumn{2}{|c|}{$R 2(N=61)$} & \multicolumn{3}{|c|}{$\mathrm{R} 3(\mathrm{~N}=61)$} & \multirow[b]{2}{*}{ NI } \\
\hline & VI & FI & $\mathrm{NI}$ & VI & FI & NI & VI & FI & \\
\hline Keyboarding & 78.7 & 19.7 & 1.6 & 91.8 & 6.6 & 1.6 & $\mathrm{C}$ & - & - \\
\hline Proofreading & 82.0 & 14.8 & 3.3 & 95.1 & 1.6 & 3.3 & $\mathrm{C}$ & - & - \\
\hline Written Communication Skills & 95.1 & 4.9 & 0.0 & 96.7 & 3.3 & 0.0 & $\mathrm{C}$ & - & - \\
\hline Oral Communication & 90.2 & 8.2 & 1.6 & 98.4 & 1.6 & 0.0 & $\mathrm{C}$ & - & - \\
\hline Records Management & 40.7 & 57.6 & 1.7 & 36.7 & 63.3 & 0.0 & 52.5 & 47.5 & 0.0 \\
\hline Word Processing & 86.9 & 11.5 & 1.6 & 98.4 & 1.63 & 0.0 & $\mathrm{C}$ & - & - \\
\hline Spreadsheets & 50.8 & 44.3 & 4.9 & 85.2 & 14.9 & 0.0 & C & - & - \\
\hline Databases & 54.1 & 44.3 & 1.6 & 93.4 & 6.6 & 0.0 & C & - & - \\
\hline Graphics & 36.1 & 50.8 & 13.1 & 23.0 & 77.0 & 0.0 & 24.6 & 75.4 & 0.0 \\
\hline Accounting Software & 39.3 & 54.1 & 6.6 & 32.8 & 63.9 & 3.3 & 23.0 & 75.4 & 1.6 \\
\hline Desktop Publishing & 31.1 & 60.7 & 8.2 & 23.0 & 75.4 & 1.6 & 27.9 & 70.5 & 1.6 \\
\hline Decision Support Software & $*$ & $*$ & $*$ & 29.5 & 59.0 & 11.5 & 13.1 & 82.0 & 4.9 \\
\hline CAD/Engineering Software & $*$ & $*$ & $*$ & 18.3 & 48.3 & 33.3 & 3.3 & 62.3 & 34.4 \\
\hline Business Statistics & 9.8 & 80.3 & 9.8 & 6.6 & 86.9 & 6.6 & 13.1 & 75.4 & 11.5 \\
\hline Research Methods & 13.1 & 72.1 & 14.8 & 9.8 & 82.0 & 8.2 & 11.5 & 83.6 & 4.9 \\
\hline Telecommunications & 60.7 & 37.7 & 1.6 & 88.5 & 11.5 & 0.0 & 90.2 & 9.8 & 0.0 \\
\hline Office Environment Planning/Design & 31.1 & 60.7 & 8.2 & 21.3 & 78.7 & 0.0 & 27.9 & 70.5 & 1.6 \\
\hline Systems Analysis & 42.6 & 47.5 & 9.8 & 13.1 & 78.7 & 8.2 & 23.0 & 72.1 & 4.9 \\
\hline Equipment Selection & 47.5 & 39.3 & 8.2 & 32.8 & 62.3 & 4.9 & 49.2 & 45.9 & 4.9 \\
\hline Software Evaluation & 52.5 & 39.3 & 8.2 & 90.2 & 4.9 & 4.9 & $\mathrm{C}$ & - & - \\
\hline
\end{tabular}


Table 4 (cont'd)

\begin{tabular}{|c|c|c|c|c|c|c|c|c|c|}
\hline \multirow{2}{*}{ Competencies } & \multicolumn{3}{|c|}{$\mathrm{R} I(\mathrm{~N}=151)$} & \multicolumn{2}{|c|}{$\mathrm{R} 2(\mathrm{~N}=102)$} & \multicolumn{3}{|c|}{$\mathrm{R} 3(\mathrm{~N}=97)$} & \multirow[b]{2}{*}{ NI } \\
\hline & VI & FI & NI & VI & FI & NI & VI & FI & \\
\hline Training Skills & 59.0 & 36.1 & 4.9 & 90.2 & 8.2 & 1.6 & C & - & - \\
\hline Computer Programming & 29.5 & 41.0 & 29.5 & 11.5 & 67.2 & 21.3 & 6.6 & 72.1 & 21.3 \\
\hline Business Ethics & 62.3 & 36.1 & 1.6 & 90.2 & 9.8 & 0.0 & C & - & - \\
\hline Voice Processing Management & 27.9 & 65.6 & 6.6 & 27.9 & 68.9 & 3.3 & 21.3 & 78.7 & 0.0 \\
\hline Supervisory Skills & 55.7 & 39.3 & 4.9 & 86.9 & 13.1 & 0.0 & 86.9 & 13.1 & 0.0 \\
\hline Support Systems Analysis & $*$ & $*$ & $*$ & 23.0 & 67.2 & 9.8 & 29.5 & 70.5 & 0.0 \\
\hline Project Management & $*$ & $*$ & $*$ & 47.5 & 42.6 & 9.8 & 82.0 & 16.4 & 1.6 \\
\hline Time Management & $*$ & $*$ & $*$ & 85.2 & 14.8 & 0.0 & 96.7 & 3.3 & 0.0 \\
\hline Work Flow Analysis & $*$ & $*$ & $*$ & 49.2 & 47.5 & 3.3 & 86.7 & 11.7 & 1.7 \\
\hline Hardware Configuration & $*$ & $*$ & $*$ & 19.77 & 63.9 & 16.4 & 18.0 & 78.7 & 3.3 \\
\hline Business Process Design & * & * & * & 13.1 & 77.0 & 9.8 & 8.3 & 90.0 & 1.7 \\
\hline Operating Systems & $*$ & $*$ & $*$ & 50.8 & 39.3 & 9.8 & 86.9 & 11.5 & 1.6 \\
\hline Micrographics/Electronic Imaging & $*$ & $*$ & $*$ & 8.2 & 73.8 & 18.0 & 4.9 & 88.5 & 6.6 \\
\hline Team Building Skills & $*$ & * & $*$ & 77.0 & 23.0 & 0.0 & 86.9 & 13.1 & 0.0 \\
\hline
\end{tabular}

Note I: Asterisks in some categories for Round One indicate competencies which did not appear in that round. These competencies were included in subsequent rounds as a result of Round One responses.

Note II: "C" indicates the point where consensus ( 85 percent) was reached in the previous round and the element was dropped from subsequent rounds.

VI = Very Important

FI = Fairly Important

$\mathrm{NI}=$ Not Important 
Table 5

Frequencies in Percentages for Occupations: All Respondents

\begin{tabular}{|c|c|c|c|c|c|c|c|}
\hline \multirow[b]{2}{*}{ Occupations } & \multicolumn{3}{|c|}{ Round $1(\mathrm{~N}=151)$} & \multicolumn{2}{|c|}{ Round $2(\mathrm{~N}=102)$} & \multicolumn{2}{|c|}{ Round $3(\mathrm{~N}=97)$} \\
\hline & I & $\mathrm{E}$ & $\mathbf{N}$ & I & $\mathrm{E}$ & $I$ & $\mathrm{E}$ \\
\hline Administrative Assistant & 50.3 & 48.3 & 1.3 & 92.1 & 7.9 & C & -- \\
\hline WP Supervisor & 17.9 & 81.5 & 0.7 & 13.9 & 86.1 & -- & $\mathrm{C}$ \\
\hline LAN Manager & 6.6 & 84.8 & 8.6 & 9.0 & 91.0 & -- & $\mathrm{C}$ \\
\hline WP Operator & 82.8 & 2.6 & 14.6 & 100.0 & 0.0 & $\mathrm{C}$ & -- \\
\hline Trainer & 19.5 & 78.5 & 2.0 & 16.8 & 83.2 & 10.3 & 89.7 \\
\hline Training Manager & 2.7 & 91.9 & 5.4 & 5.1 & 94.9 & - & $\mathrm{C}$ \\
\hline Systems Analyst & 16.9 & 66.2 & 16.9 & 4.0 & 96.0 & -- & $\mathrm{C}$ \\
\hline Records Manager & 47.0 & 50.3 & 2.6 & 27.7 & 72.3 & 14.4 & 85.6 \\
\hline Office Manager & 19.3 & 78.7 & 2.0 & 13.0 & 87.0 & - & $\mathrm{C}$ \\
\hline Information Manager & 18.0 & 75.3 & 6.7 & 11.1 & 88.9 & -- & $\mathrm{C}$ \\
\hline Records Analyst & ++ & ++ & ++ & 41.2 & 58.8 & 13.4 & 86.6 \\
\hline Admin. Services Supervisor & ++ & ++ & ++ & 21.2 & 78.8 & 9.3 & 90.7 \\
\hline Business Procedures Analyst & ++ & ++ & ++ & 32.7 & 67.3 & 10.3 & 89.7 \\
\hline Office Automation Analyst & ++ & ++ & ++ & 42.9 & 57.1 & 10.3 & 89.7 \\
\hline Information Specialist & ++ & ++ & ++ & 48.0 & 52.0 & 11.3 & 88.7 \\
\hline Jr. Records Mgt. Consultant & ++ & ++ & ++ & 76.0 & 24.0 & 30.9 & 69.1 \\
\hline
\end{tabular}

"I" signifies that the new program graduate could enter this occupation immediately after graduation "E" signifies that some experience would be necessary before the graduate could qualify for this position. "N" signifies "never" and was used only in Round One in order to eliminate inaapropriate occupations. $"++$ " signifies that this occupation was added after Round One following suggestions from respondents. " $\mathrm{C}$ " signifies that concensus ( 85 percent) was reached in the previous round. 
Table 6

Frequencies in Percentages for Occupations: Respondents to All Three Rounds

\begin{tabular}{|c|c|c|c|c|c|c|c|}
\hline \multirow[b]{2}{*}{ Occupations } & \multicolumn{3}{|c|}{ Round $1(\mathrm{~N}=61)$} & \multicolumn{2}{|c|}{ Round $2(\mathrm{~N}=61)$} & \multicolumn{2}{|c|}{ Round $3(\mathrm{~N}=61)$} \\
\hline & I & $\mathrm{E}$ & $\mathbf{N}$ & I & $\mathbf{E}$ & I & $\mathbf{E}$ \\
\hline Administrative Assistant & 57.6 & 39.0 & 3.4 & 93.4 & 6.6 & $\mathrm{C}$ & -- \\
\hline WP Supervisor & 19.7 & 76.7 & 1.6 & 10.0 & 90.0 & -- & $\mathrm{C}$ \\
\hline LAN Manager & 6.6 & 85.2 & 8.2 & 6.7 & 93.3 & -- & $\mathrm{C}$ \\
\hline WP Operator & 86.9 & 0.0 & 13.1 & 100.0 & 0.0 & $\mathrm{C}$ & -- \\
\hline Trainer & 20.0 & 76.7 & 3.3 & 9.8 & 90.2 & 14.8 & 85.2 \\
\hline Training Manager & 3.3 & 88.3 & 8.3 & 3.3 & 96.7 & .. & $\mathrm{C}$ \\
\hline Systems Analyst & 18.6 & 69.5 & 11.9 & 1.7 & 98.3 & -- & $\mathrm{C}$ \\
\hline Records Manager & 47.5 & 47.5 & 4.9 & 19.7 & 80.3 & 14.8 & 85.2 \\
\hline Office Manager & 25.0 & 70.0 & 5.0 & 8.2 & 91.8 & - & $\mathrm{C}$ \\
\hline Information Manager & 19.7 & 72.1 & 8.2 & 5.0 & 95.0 & -- & C \\
\hline Records Analyst & ++ & ++ & ++ & 36.2 & 63.8 & 9.8 & 90.2 \\
\hline Admin. Services Supervisor & ++ & ++ & ++ & 16.7 & 83.3 & 11.8 & 88.5 \\
\hline Business Procedures Analyst & ++ & ++ & ++ & 23.7 & 76.3 & 9.8 & 90.2 \\
\hline Office Automation Analyst & ++ & ++ & ++ & 35.6 & 64.4 & 6.6 & 93.4 \\
\hline Information Specialist & ++ & ++ & ++ & 39.0 & 61.0 & 14.8 & 85.2 \\
\hline Jr. Records Mgt. Consultant & ++ & ++ & ++ & 78.3 & 21.7 & 32.8 & 67.2 \\
\hline
\end{tabular}

"l" signifies that the new program graduate could enter this occupation immediately after graduation

"E" signifies that some experience would be necessary before the graduate could qualify for this position.

"N" signifies "never" and was used only in Round One in order to eliminate inaapropriate occupations.

"++" signifies that this occupation was added after Round One following suggestions from respondents.

" $\mathrm{C}$ " signifies that concensus ( 85 percent) was reached in the previous round. 
not unexpected when one considers that the graduates will be prepared to be end-user specialists rather than software developers, it is surprising that certain other areas were not assigned a higher degree of importance. For example, only slightly fewer than $51.5 \%$ of third-round respondents selected records management as being very important, and $48.5 \%$ thought it was only fairly important. (At the same time, over $85 \%$ felt that graduates with some experience could fill positions as records managers.) Since this is an area which is generally considered by those in the field of information management to be an integral part of information management, it was expected to receive a higher rating, particularly when comments were included on the questionnaire in the final round suggesting that it might be of greater importance than was previously assigned by respondents.

Voice processing management, despite the growing importance of voice mail in organizations and lack of training available, was selected as very important by only $23.7 \%$ of respondents in Round Three. It is possible, however, that this also indicates an imcomplete understanding of the area. One potentially valuable benefit of this study has been the development of good rapport with many respondents, and people in industry in particular. Many respondents took sufficient interest in the project that they wrote frequent comments and suggestions and were prepared to spend a significant amount of time completing questionnaires.

A considerable amount of information concerning basic components of the new courses has been acquired. While it would have been preferable to have a larger sample from industry, nevertheless the general feedback has been, for the most part, informed and enthusiastic. Some skills components, such as keyboarding and word processing, have appeared as having greater importance than was envisioned in the revised program. Confirmation has been received that excellent oral and written communication skills are essential for the new graduate and that these competencies must play a major role in the curriculum. Knowledge of software applications such as spreadsheets and databases was emphasized, though, surprisingly, graphics and desktop publishing were not. Possibly, these areas are still restricted to specialized types of work and only in select organizations. The high importance attached to elements such as teambuilding skills, project management, and time management suggests that "people skills" are becoming more important in the workplace and should be incorporated in the program.

The low group rating for records management was of some concern. The present intention is to incorporate a minimum of four courses in records 
management in the new information management program. It is possible that the low rating from many respondents could indicate a misinterpretation of what the field includes. There is a tendency in some areas of business to think of records management as "filing."

Information received concerning occupations has helped to give some comfort to the department that new graduates will find employment in a variety of areas and that there is a real need for individuals with such specialized education. While there is still some resistance to change from the present program on the part of some subgroups, generally the results indicate that the direction in which this department is moving is appropriate for the conditions and situations in today's business world.

\section{Recommendations}

Further inquiry is needed into the appropriateness of including a large concentration of records management in an information management program. There is a need to confirm that the program is serving regional business needs by offering these courses. If the new program is to include a large component of records management, the department might be well advised to include some more detailed descriptions of the records management courses in its promotional literature.

A need has been identified for greater promotion of the program in order better to inform various groups of what the program is, and will be, offering.

It was recommended that, since the direction in which this department is moving is unique in the particular geographic area, a follow-up study should be done starting from the time that the first graduates of this program begin employment. This could provide much valuable feedback both to the university, employers, and future students.

\section{Discussion of the Delphi Technique}

What is an appropriate response rate? This is a common question asked of Delphi studies and there is no simple answer. Excellent response rates are possible by providing the appropriate incentive. For example, in one study (Uhl,1971) 305 of 326 university students participated in all three rounds. Each student received a cheque upon completion of all rounds. Clearly this type of incentive is not always possible, nor is a $94 \%$ rate of return always necessary. It depends on the objectives of the study. For example, in the study reported here, five groups were included. Different response rates were expected for these different groups. On the first questionnaire it was expected that over $70 \%$ of the 
present students and the Advisory Board would participate $(85 \%$ and $75 \%$ participated). In contrast, the first questionnaire was sent to a large number of graduates because it was expected that many would be returned because of inaccurate mailing addresses. Another group consisted of school counsellors. The purpose of including school counselors was to introduce them to the new curriculum so they could be more knowledgeable in advising high school students. Thus, as many counsellors as feasible were selected. When only $17 \%$ completed the first questionnaire, the objective for this group was clearly not met, and action was taken to increase this group's participation. The objective was not to obtain a more representative sample, but to educate more counselors. One must also consider the attrition from one round to the next. If the study is of interest, there will be less attrition between rounds than on the first round. However, other factors may influence participation. In this study, a number of the business people were transferred or given different responsibilities as their company made adjustments to the hard economic times. The attrition from round to round should be of concern because some people could drop out because they disagree with the majority. If this is the situation, consensus may occur only because the people who agree remain in the study. This should be checked by comparing the first questionnaire responses of those who remain in the study with those who drop out.

There are many other questions concerned with administering the Delphi technique. For those interested in considering this technique, Uhl (1983) presents some initial planning guidelines as well as a discussion of the major steps in conducting such a study. The initial planning guidelines as stated by $\mathrm{Uhl}$ are:

1. Be certain there is not a simpler and less costly procedure that will achieve the same results.

2. Do not underestimate the time and resources needed to provide the necessary feedback.

3. Select the participants with care and in a manner consistent with the objectives of the study.

4. Use unambiuguous statements, neither too vague nor too specific, to obtain valid and efficient input from participants.

5. Do not mislead the participants.

6. Do not ignore the responses of participants who disagree with the majority. 
7. Do not impose the views and biases of the study designers on the participants.

8. Allow enough time between rounds to prepare and distribute feedback, but do not allow so much time that participants lose interest in the study.

9. Provide participants with enough incentive to remain interested throughout the study (p.88).

The major steps in a Delphi study involve identifying the project's purpose(s), establishing a project committee, selecting the participants, determining the specific methodology, developing the round one questionnaire, analyzing the round one content, processing round two, processing round three and succeeding rounds, and using the results. Each of these is discussed in detail in Uhl (1983).

\section{Conclusions}

The above is an illustration of using the Delphi process for curriculum improvement. It illustrates some advantages of the process. For example, it is possible, for the cost of postage and copying, to include quite diverse groups with differing degrees of expertise. The participants are free to select a convenient time to complete the questionnaires. Participants are provided feedback as part of the process and become more knowledgeable about the program. They also experience a sense of having assisted in developing the program and thus acquire an interest in the program. Many who participate indicate a willingness to provide further assistance, if necessary. An important by-product is the publicity given the program. Finally, in the frequent cases when convergence does not occur, groups which disagree and their reasons for disagreeing can be identified. Further education can be provided to these groups, if deemed necessary; or at the very least, a better understanding of their reasons for disagreement is obtained.

There are also some disadvantages to the Delphi technique. Since there are at least three rounds of questions, a person must have some interest in the topic to participate. A lack of interest can lead to low participation rates, as illustrated in this study. The best way to increase this rate is through an effective cover letter and at least one follow-up. Another disadvantage is that, as in this study, a few questions can remain unanswered. When this occurs, it must be determined whether the answers are worth another round of questions for all groups. In this particular study, special follow-up was done with certain groups to obtain these answers, rather than conducting another round of questions for all groups. 
It is also imperative for any Delphi process that the participants trust the moderator. Individual responses must be kept anonymous and feedback must be accurate. The moderator must be given sufficient time to perform the task.

While curriculum improvement through the Delphi technique has not been employed frequently in Canada, it is hoped that this technique will prove useful as greater emphasis is placed on quality programs at all levels.

\section{References}

Bogue, G.E. \& Saunders, R.L. (1992). The evidence for quality: Strengthening the tests of academic and administrative effectiveness. San Francisco: Jossey-Bass.

Conrad, C.F. \& Blackburn, R.T. (1985). Program quality in higher education: A revicw and critique of literature and research. In J. C. Smart (Ed.), Higher education: handbook of theory and research. New York: Agathon Press.

Nadeau, G., Donald, J., Konrad, A., Lavigne, J., \& Laveault, D. (1992). In R. Runte (Chair), Criteria and indicators of quality and excellence in Canadian colleges and universities - results of phase II of the national project. Symposium conducted at the annual meeting of the Canadian Society for the Study of Higher Education, Charlottetown.

Smith, S. (1991). Report of the commission of inquiry on Canadian university education. Ottawa: Association of Universities and Colleges of Canada.

Uhl, N.P. (1971). Identifying institutional goals. Durham, N.C.: National Laboratory for Higher Education (ERIC/ED 049713).

Uhl, N.P. (1983). Using the Delphi technique in institutional planning. In N.P. Uhl (Ed.), Using research for strategic planning (pp. 81-94). New Directions for Institutional Research, 37. San Francisco: Jossey-Bass.

Uhl, N.P. (1990). Delphi technique. In H.J. Walberg \& G.D. Hacrtel (Eds.), The international encyclopedia of educational evaluation (pp. 81-82). Oxford: Pergamon Press. 